\title{
Assessing Retinal Structure in Patients with Parkinson’s Disease
}

Jonathon B Young ${ }^{1}$, Pooja Godara ${ }^{1}$, Vesper Williams ${ }^{1}$, Phyllis Summerfelt ${ }^{1}$, Thomas B Connor ${ }^{1}$, Sergey Tarima ${ }^{2}$, Alexis Visotcky², Robert F Cooper $^{3}$, Karen Blindauer ${ }^{4}$ and Joseph Carroll1,3,5*

${ }^{1}$ Department of Ophthalmology and Visual Sciences, Medical College of Wisconsin, Milwaukee, USA

${ }^{2}$ Division of Biostatistics, Institute for Health and Equity, Medical College of Wisconsin, USA

${ }^{3}$ Department of Biomedical Engineering, Marquette University, Milwaukee, USA

${ }^{4}$ Department of Neurology, Medical College of Wisconsin, USA

${ }^{5}$ Department of Cell Biology, Neurobiology and Anatomy, Medical College of Wisconsin, USA

\begin{abstract}
Objective: The retina is an extension of the central nervous system (CNS), and ocular symptoms can precede manifestations of CNS disorders. Given that several neurodegenerative conditions that affect the brain exhibit ocular symptoms, the retina may be an accessible biomarker to monitor disease progression. Dopamine, the key neurotransmitter related to Parkinson's disease (PD), is contained in amacrine and interplexiform cells, which reside in specific retinal layers. Understanding how loss of dopaminergic cells affects retinal anatomy could be relevant for monitoring disease progression. Here, our objective is to evaluate retinal structure (foveal pit morphology and thickness) in patients with PD.
\end{abstract}

Methods: Thirty-three Caucasian subjects diagnosed with PD and 40 age-matched Caucasian control subjects underwent retinal imaging with spectral-domain optical coherence tomography (SD-OCT). Axial length measurements were used to correct the lateral scale of each macular volume scan. From these corrected volumes, foveal morphology was quantified with previously described algorithms, and Early Treatment Diabetic Retinopathy Study (ETDRS) grids of retinal thickness were generated and incorporated into a logistic regression model to predict PD.

Results: Interocular foveal morphology measurements were highly symmetrical in PD patients and control subjects. There were no significant differences in foveal pit morphology between PD patients and control subjects. Using a model incorporating sex and axial length corrected ETDRS regions, we generated a receiver operating characteristic curve with a C-statistic of 0.80 .

Conclusion: Our study, which to our knowledge is the first to properly scale OCT measurements when quantifying retinal thickness, demonstrates that PD patients retain foveal symmetry between eyes. When constructing a model to predict PD, sex, along with the center $1 \mathrm{~mm}$ and temporal outer ETDRS regions, were significant predictors of PD. In addition to proper scaling of OCT measures, gender and racial differences in retinal anatomy should be considered in building future predictive PD models when using OCT.

Keywords: Optical coherence tomography; Parkinson's disease; Fovea; Retina

\section{Introduction}

Parkinson's disease (PD) is a progressive neurological disorder resulting from selective dopaminergic neuronal loss in the substantia nigra, first described by James Parkinson in 1817 [1]. Parkinson's disease is the second most common neurodegenerative disorder following Alzheimer's Disease [2], and the prevalence of diagnosis is expected to double by 2040 [3]. Given the developmental origin of the retina, it is not surprising that there are a variety of visual symptoms associated with PD, including abnormal contrast sensitivity, motion perception abnormalities, impaired visual acuity, color vision deficits, and visual hallucinations $[4,5]$. The loss of retinal dopaminergic cells is thought to underlie the visual dysfunction observed in PD [6]. Dopamine is contained in amacrine and interplexiform cells, which reside in the inner nuclear layer (INL) and inner plexiform layer (IPL) of the retina, respectively [7]. Understanding how loss of dopaminergic cells affects retinal anatomy in PD could be relevant for monitoring disease progression, assessing therapeutic response to treatment, or facilitating early detection of the disease.

The human retina can be examined non-invasively using spectral domain optical coherence tomography (SD-OCT) [8,9], thus this technique has been proposed as a way to monitor PD within the retina [10-29]. There are a large number of studies using SD-OCT in PD patients, but they have provided conflicting results. For example, retinal thickness has been suggested by some to be reduced in PD patients versus controls $[10,15,18]$, while others report no significant difference in total retinal thickness $[11,21,24]$. A major advantage of SD-OCT is its ability to resolve individual cellular layers in the retina, though even sublayer analyses in PD patients have yielded discrepant results. Many studies have documented retinal nerve fiber layer (RNFL) thinning in PD patients versus age-matched controls [15-18, 22,23,25,30], though other reported no significant RNFL thinning[10,19,21]. Results from other inner retinal layers are similarly variable. For example, thinning of the inner retinal layers including the ganglion cell layer (GCL) and IPL of PD patients has been reported [13,24]. Lee et al. observed thinning of the INL [21], while Garcia-Martin et al. observed increased thickness in the INL with thinning in the GCL and IPL when comparing PD patients with healthy subjects [15]. Živković et al. and Sari et al. both documented statistically significant thinning in the GCL-IPL layer compared to controls $[26,27]$. Sari et al. noted an inverse correlation

*Corresponding author: Dr. Joseph Carroll, Medical College of Wisconsin, The Eye Institute, Milwaukee, USA, Tel: +1-414-955-2052; E-mail: jcarroll@mcw.edu

Received February 01, 2019; Accepted February 28, 2019; Published March 07 2019

Citation: Young JB, Godara P, Williams V, Summerfelt P, Connor TB, et al (2019) Assessing Retinal Structure in Patients with Parkinson's Disease. J Neurol Neurophysiol 10: 485. doi:10.4172/2155-9562.1000485

Copyright: @ 2019 Young JB, et al. This is an open-access article distributed under the terms of the Creative Commons Attribution License, which permits unrestricted use, distribution, and reproduction in any medium, provided the original author and source are credited. 
with PD severity and duration, while Živković et al. did not observe this occurrence. In a five year retinal reevaluation using SD-OCT, Satue et al. found significant changes compared to baseline in 7 of 9 Early Treatment Diabetic Retinopathy Study (ETDRS) thickness regions, and 2 of 6 regions of the RNFL [28].

Foveal morphology, which represents in some way the topography of multiple retinal layers, has also been studied in patients with PD. Spund et al. provided data showing that the foveal pit becomes broader and thinner in patients with PD [12] and Ding et al. showed that PD patients could be discriminated from normal controls based on foveal morphology, with a specificity of $70 \%$ [14].

Three factors might contribute to the discrepant findings in previous studies. First, previous reports did not take into account inter-individual variability in axial length. Variability in axial length can affect the lateral scale of OCT data from some devices and scaling each measurement to the patient's axial length is crucial to ensure the accuracy of each measurement. For example, Odell et al. showed that failing to correct for axial length in data from the Cirrus HD-OCT can lead to errors in the ETDRS thickness measurements of greater than 40 microns [31]. To the best of our knowledge, no commercially available OCTs correct for inter-individual differences in axial length when generating macular thickness maps. If the retina is going to be used as a biomarker for PD, the sensitivity of this measurement needs to be as accurate as possible to prevent misclassification of a condition. Second, the type of OCT device used has not been consistent in all forms of retinal evaluation with PD. Statistically significant differences in specific macular regions and correlations with disease duration detected on one device may not be statistically significant when using an alternate SD-OCT machine $[17,18]$. Third, differences in retinal layer segmentation (automated vs. manual) could contribute to discrepant results.

The purpose of the present study was to use axial length scaled SD-OCT volumes to compare foveal morphology and retinal thickness in PD patients versus age-matched control subjects. These retinal evaluations were then placed into a logistic regression model and cross-validation analysis was performed to determine our accuracy in predicting PD. Based on these findings, we propose that OCT devices enable either an export of raw thickness data for offline manipulation or an onboard correction of individual differences in ocular biometry. From these data files, algorithms can be applied to better predict the diagnosis of $\mathrm{PD}$, potentially offering earlier detection of this condition.

\section{Methods}

\section{Subjects}

All research involving human subjects followed the tenets of the Declaration of Helsinki and was approved by the Institutional Review Board at the Medical College of Wisconsin. PD patients were referred by a neurologist and asked to participate in our study following his or her neurology exam. All subjects gave informed consent after explanation of risks and possible benefits of the study. A total of 62 patients diagnosed with PD were recruited for this study, along with 40 age-matched healthy control (HC) subjects. PD and HC subjects were excluded from the study if previous retinal pathology had been documented by a physician or was identified via a self-report questionnaire. Twentynine of the 62 PD patients were excluded from further analyses for a variety of reasons including: patient consented but then refused ocular imaging, poor OCT signal quality, artifacts in OCT macular thickness map, and ocular pathology detected (epiretinal membrane, glaucoma) or reported via a self-report questionnaire. Thirty-three Caucasian patients diagnosed with PD and 40 age-matched Caucasian control subjects were further analyzed for this work.

Both eyes were imaged in PD patients. Of the $40 \mathrm{HC}$ subjects, 7 had only one eye included in the study due to available data or low signal quality. OCT scans were also reviewed for retinal abnormalities, and the left eye of 1 PD subject with a retinal abnormality was excluded from the analysis. The left eye of 3 additional PD subjects was excluded from analysis due to concurrent self-reported ocular pathology. The average age of PD patients $( \pm 1 S D)$ was $64.6 \pm 10.1$ years. The average age of HC subject was 61.9 years \pm 10.9 years. Table 1 provides additional demographic data for PD patients. PD patients self-reported ocular history, but age of PD diagnosis and current medications were confirmed by completing a subject chart review. The motor Unified Parkinson's Disease Rating (UPDR) Scale scores were documented in 28 of 33 PD subjects to indicate disease severity (Table 1 ). The average age at $\mathrm{PD}$ diagnosis was 60.5 years. If the age of the PD diagnosis could not be confirmed, the age of the subject's first visit to Froedtert \& the Medical College of Wisconsin was reported. The average time from PD diagnosis until time of imaging was 4.1 years.

Color vision was tested with the Richmond HRR test [32] and/or Neitz Test of Color Vision [33]. For the PD patients, 14/33 made one or more errors on the Neitz test. All who made errors were subsequently tested using the Richmond HRR test, on which they made no errors. Color vision testing for normal controls was not uniform, as they were included from various previous studies, with two subjects not having any documented color vision testing performed. Of the remaining 38 normal controls, two made errors on both the Neitz and Richmond HRR tests (one making errors consistent with a protan defect and the other making mild nonspecific red/green errors). In addition, 14 normal controls made one or more errors on the Neitz test. Four of these 14 were subsequently tested with the HRR and made no errors.

\section{SD-OCT imaging \& measuring foveal pit morphology}

Volumetric images of the macula were obtained using the Cirrus ${ }^{\mathrm{TM}}$ HD-OCT (Carl Zeiss Meditec, Dublin, California, USA) system. Exclusion criteria included diagnosis of retinal pathology, OCT signal quality below $7 / 10$, and inability to maintain stable fixation as documented by segmentation errors found in OCT scans. For PD patients, macular scan quality averaged $9.27 \pm 0.90$ for the right eye, and $9.48 \pm 0.62$ for the left eye. In controls, macular scan quality averaged $9.28 \pm 0.81$ for the right eye and $9.45 \pm 0.86$ for the left eye. SD-OCT scans were reviewed by an ophthalmologist for any signs of retinal pathology, and seven of the $33 \mathrm{PD}$ patients showed class one drusen [34]. As described in Wagner-Schuman et al., we corrected the lateral scale of all OCT data sets for inter-individual differences in axial length [35]. We obtained axial length measurements using low coherence interferometry (IOLMaster, Carl Zeiss Meditec). We multiplied $6 \mathrm{~mm}$ (nominal scan length) by the ratio of the subject's axial length to that assumed by the Cirrus ${ }^{\mathrm{TM}}$ HD-OCT system $(24.46 \mathrm{~mm})$ in order to derive the actual scan lengths. For PD patients, axial length measurements ranged from 21.40 to $27.89 \mathrm{~mm}$. Consequently, actual scan lengths measured 5.25 to $6.84 \mathrm{~mm}$. For HC subjects, axial length measurements ranged from 21.55 to $26.95 \mathrm{~mm}$, and therefore actual scan lengths measured from 5.29 to $6.61 \mathrm{~mm}$.

As previously described [35], the location of the fovea within each volume scan was identified automatically using the onboard foveafinder algorithm of the Cirrus. The coordinates of the foveal center and the retinal thickness data from the volume scans were exported for offline analysis (Cirrus Research Browser; Carl Zeiss Meditec). Custom 

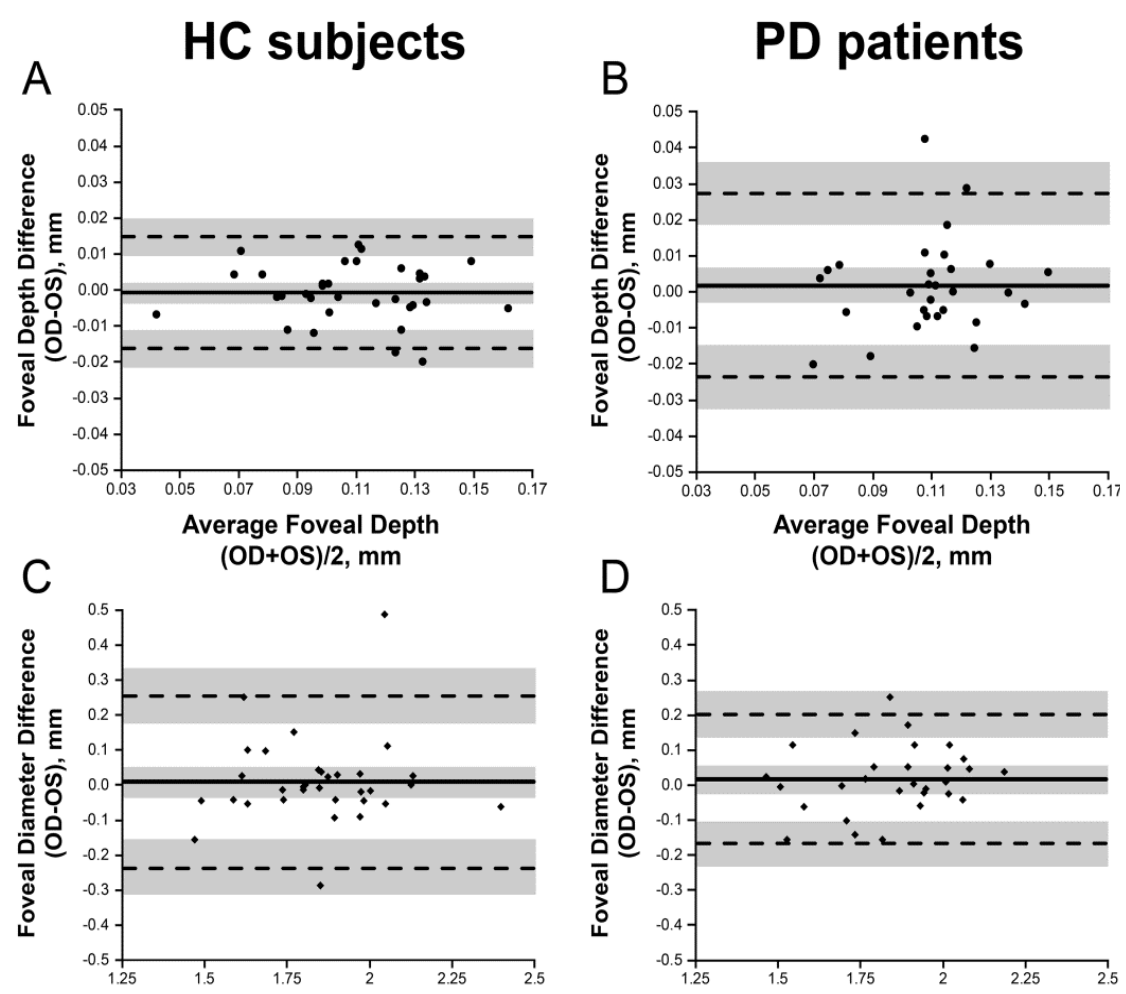

D

$(\mathrm{OD}+\mathrm{OS}) / 2, \mathrm{~mm}$

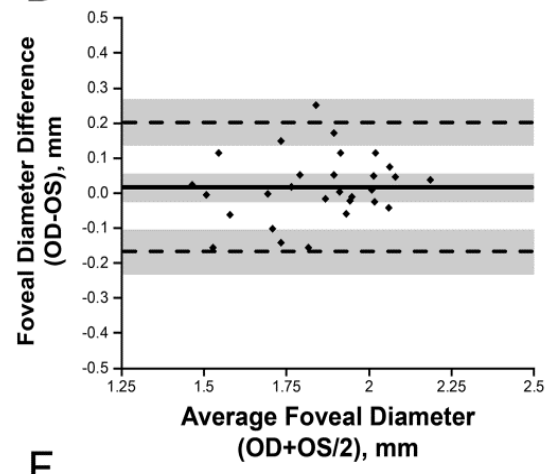

$\mathrm{E}$

$(\mathrm{OD}+\mathrm{OS} / 2), \mathrm{mm}$
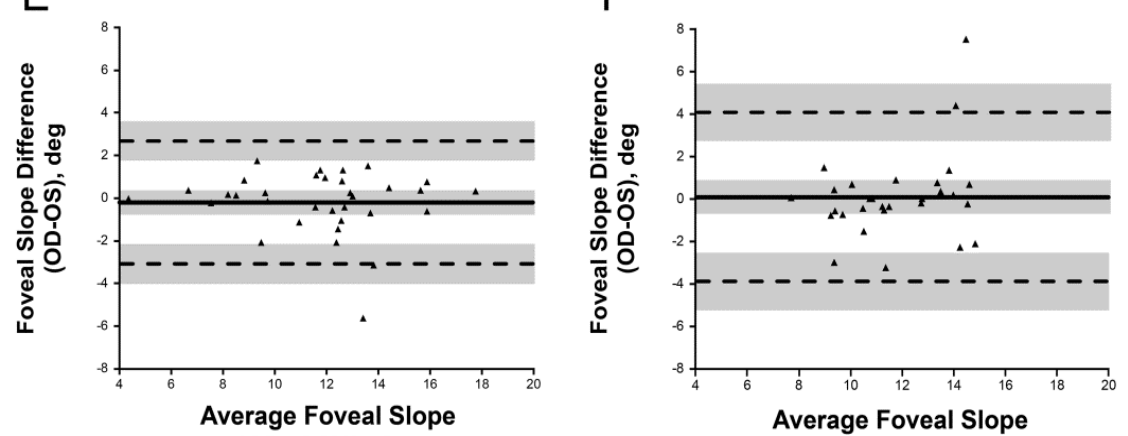

G $(\mathrm{OD}+\mathrm{OS}) / 2$, deg
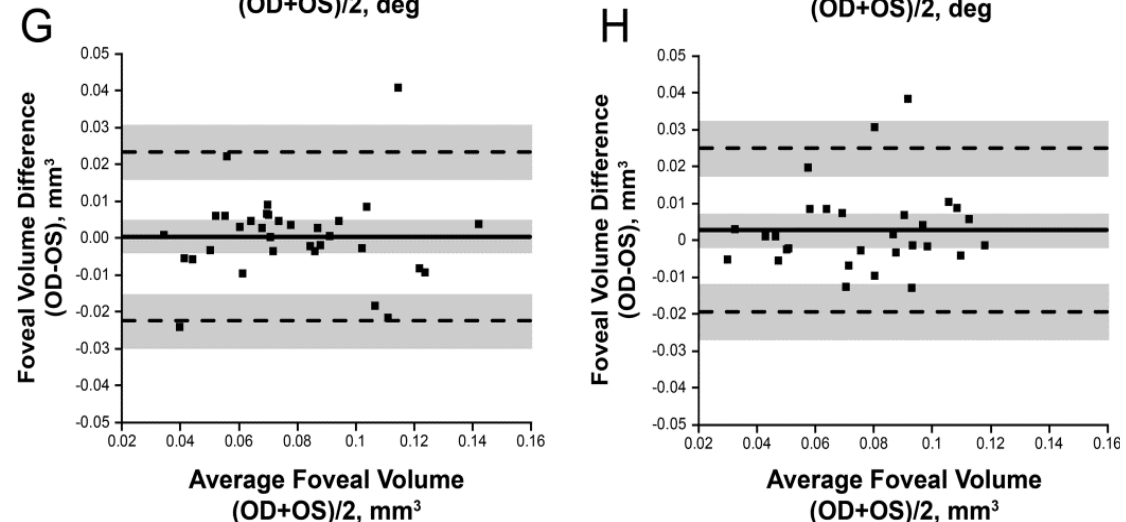

Figure 1: Interocular symmetry of foveal morphology in HC Subjects (A, C, E, G)) and PD Patients (B, D, F, H). Bland-Altman plots for foveal pit depth (A, B), diameter $(C, D)$, slope $(E, F)$, and volume $(G, H)$. For PD patients, the absolute mean difference between eyes (OD minus OS; solid line in each plot) was less than 0.0019 $\mathrm{mm}$ for pit depth, less than $0.0171 \mathrm{~mm}$ for pit diameter, less than 0.095 degrees for foveal slope, and less than $0.0029 \mathrm{~mm}^{3}$ for foveal volume. For HC subjects, the absolute mean difference was less than $0.0007 \mathrm{~mm}$ for pit depth, less than $0.0095 \mathrm{~mm}$ for pit diameter, less than 0.2063 degrees for foveal slope, and less than $.0006 \mathrm{~mm}^{3}$ for foveal volume. The mean difference is represented by the solid black line, while the dashed lines represent the $95 \%$ limits of agreement (LOA) for the bias. Shaded regions represent the confidence limits on the bias and LOA. There was no apparent relationship between the mean difference and the magnitude of the measurement. 


\section{HC subjects}

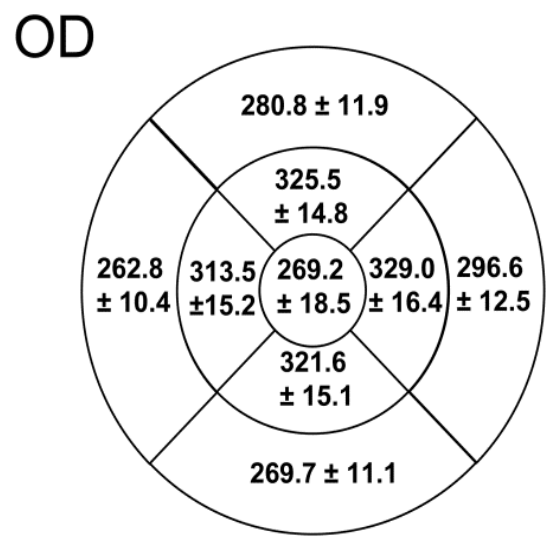

OS

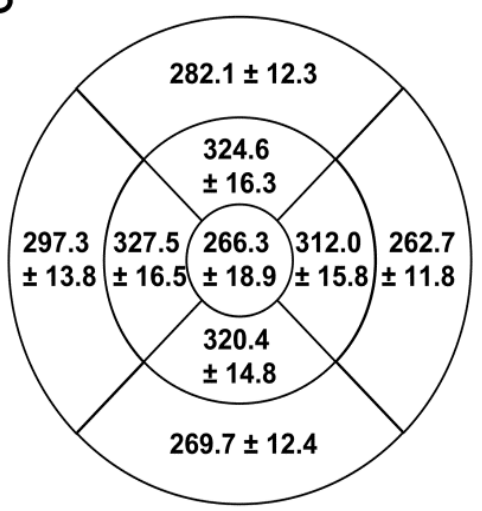

\section{PD patients}
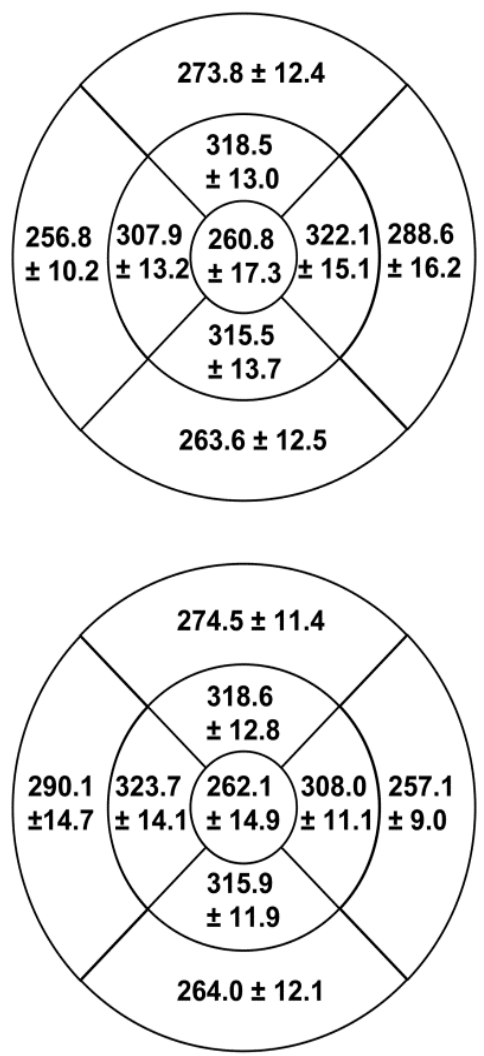

Figure 2: Ocular biometry corrected Early Treatment Diabetic Retinopathy Study (ETDRS) thickness maps for HC subjects and PD patients. PD patients have thinner retinas compared to HC subjects. The ETDRS measurements of all eyes were included in the analysis to help establish collinear predictors of PD. The measurements of all ETDRS regions were highly correlative as shown in Supplementary Table 2.

software was created to generate revised Early Treatment Diabetic Retinopathy Study (ETDRS) thickness maps (MatLab; The MathWorks, Natick; MA), which incorporated the actual axial length and retinal thickness data for each subject. Each thickness map used for analysis was aligned to the center of the fovea, not necessarily the center of the OCT volume. Foveal pit morphology was quantified using a previously described difference-of-Gaussian algorithm [36].

\section{Statistical Analysis}

Statistical analysis was performed using GraphPad Prism (GraphPad, La Jolla, CA) and R 3.3.1 (www.r-project.org). The D'Agostino \& Pearson normality test was used to assess if these measurements were normally distributed. Since all foveal metrics were normally distributed, Bland-Altman plots [37-38] and a Student's $\mathrm{t}$-test were used to analyze the data. Values of $\mathrm{p}<0.05$ would indicate statistically significant findings.

To build a parsimonious model predicting $\mathrm{PD}$, the forward variable selection method was used to identify a model with the smallest Akaike information criteria (AIC). Then, the predictive properties of this model were evaluated with the $\mathrm{C}$ statistic (Area under Receiver Operating Characteristic $\{$ ROC $\}$ Curve). The ROC curve along with the C-statistic were internally validated using leave one out cross-validation technique (LOOCV). Due to previous studies showing that females have thinner retinas, sex was later added as an additional predictor to this model in subsequent analysis, which led to a new parsimonious model. Similarly, LOOCV cross-validation was applied to the ROC and the C-statistic.

\section{Results}

\section{Foveal pit morphology remains symmetrical in PD}

We first compared foveal pit morphology between PD patients and HC subjects and determined if measurements were symmetrical between eyes. To test this, we used a Bland-Altman plot for all foveal metrics calculations to determine the agreement between eyes. As shown in Figure 1, the mean difference between eyes was close to zero for all foveal pit parameters. Only one $\mathrm{HC}$ subject and one PD patient fell outside the limits of agreement, and the similarity between measurements appears to indicate a lack of foveal rearrangement between eyes.

Following confirmation of interocular symmetry between eyes of PD patients and HC subjects, the foveal metrics were subsequently compared between groups (Table 2). There was no statistical difference in any of the foveal metrics assessed. Together, these results suggest the fovea retains interocular symmetry in our sample of PD patients.

\section{Logistic regression models to predict Parkinson's disease}

As the fovea remains symmetrical in our observed cases of PD, 
Citation: Young JB, Godara P, Williams V, Summerfelt P, Connor TB, et al. (2019) Assessing Retinal Structure in Patients with Parkinson's Disease. J Neurol Neurophysiol 10: 485. doi:10.4172/2155-9562.1000485

Page 5 of 7

\begin{tabular}{|c|c|c|c|c|c|c|c|}
\hline Subject & $\begin{array}{c}\text { Age }^{*} \\
\text { (years) }\end{array}$ & Sex & $\begin{array}{l}\text { UPDRS Motor } \\
\text { Examination }\end{array}$ & $\begin{array}{l}\text { Age at PD } \\
\text { Diagnosis }\end{array}$ & On Levodopa & $\begin{array}{l}\text { Age when DOPA } \\
\text { started }\end{array}$ & Other Medications \\
\hline JC_0702 & 44 & $\mathrm{~F}$ & ND & 40 & Yes & 43 & \\
\hline JC_0703 & 66 & $\mathrm{~F}$ & 33 & $65^{\star *}$ & Yes & 65 & Amantadine \\
\hline JC_0705 & 65 & $\mathrm{~F}$ & 10 & 60 & No & -- & Amantadine \\
\hline JC_0706 ${ }^{\ddagger}$ & 57 & $M$ & ND & 57 & Yes & 57 & Ropinirole \\
\hline JC_0708 & 53 & $M$ & 13 & 51 & Yes & 51 & \\
\hline JC_0709' & 51 & $M$ & 16 & 43 & Yes & 46 & \\
\hline JC_0710 & 56 & $\mathrm{~F}$ & 37 & 53 & No & -- & Ropinirole \\
\hline JC_0712 & 54 & M & 8 & $53^{* *}$ & No & -- & $\begin{array}{l}\text { Amantadine; } \\
\text { Pramipexole }\end{array}$ \\
\hline JC_0715 & 87 & $\mathrm{~F}$ & 35 & $84^{* *}$ & Yes & 84 & \\
\hline JC_0719 & 77 & $M$ & 24 & 75 & Yes & 76 & \\
\hline JC_0721 & 71 & $\mathrm{~F}$ & 4 & $67^{* *}$ & Yes & 67 & \\
\hline JC_0724 & 49 & $M$ & 25 & 40 & Yes & 40 & Ropinirole \\
\hline JC_0725 ${ }^{\dagger}$ & 78 & $M$ & ND & 73 & Yes & 75 & \\
\hline JC_0727 & 61 & $M$ & 7 & 57 & Yes & 61 & Ropinirole \\
\hline JC_0728 & 68 & $M$ & 16 & 57 & Yes & 62 & \\
\hline JC_0729 & 70 & $\mathrm{~F}$ & 21 & 64 & Yes & 64 & \\
\hline JC_0731 & 76 & $\mathrm{~F}$ & 11 & 74 & Yes & 74 & \\
\hline JC_0733§ & 79 & $\mathrm{~F}$ & ND & $67^{\star *}$ & Yes & 67 & $\begin{array}{l}\text { Amantadine; } \\
\text { Ropinirole }\end{array}$ \\
\hline JC_0737 & 59 & M & 23 & 56 & Yes & 56 & $\begin{array}{l}\text { Entacapone; } \\
\text { Ropinirole }\end{array}$ \\
\hline JC_0738 & 71 & $M$ & 16 & 69 & Yes & 69 & \\
\hline JC_0739 & 64 & M & 9 & 62 & Yes & 62 & $\begin{array}{l}\text { Amantadine; } \\
\text { Selegiline }\end{array}$ \\
\hline JC_0743 & 61 & $\mathrm{~F}$ & 14 & 60 & Yes & 60 & \\
\hline JC_0745 & 64 & M & ND & 58 & Yes & 60 & $\begin{array}{l}\text { Trihexyphendiyl; } \\
\text { Ropinirole }\end{array}$ \\
\hline JC_0748 & 76 & $M$ & 9 & 75 & Yes & 75 & \\
\hline JC_0750 & 56 & $M$ & 13 & 53 & No & -- & Pramipexole \\
\hline JC_0950 & 53 & M & 6 & 46 & Yes & 46 & $\begin{array}{l}\text { Amantadine; } \\
\text { Rasagiline }\end{array}$ \\
\hline JC_0951 & 70 & $\mathrm{~F}$ & 19 & 69 & Yes & 69 & \\
\hline JC_0953 & 53 & $\mathrm{~F}$ & 5 & 48 & No & -- & $\begin{array}{l}\text { Amantadine; } \\
\text { Rasagiline; } \\
\text { Ropinirole }\end{array}$ \\
\hline JC_0955 & 76 & $M$ & 31 & 72 & Yes & 74 & \\
\hline JC_0957 & 58 & M & 14 & 57 & No & -- & $\begin{array}{l}\text { Amantadine; } \\
\text { Pramipexole }\end{array}$ \\
\hline JC_0958 & 70 & $M$ & 19 & 66 & Yes & 66 & Amantadine \\
\hline JC_0959 & 70 & M & 23 & 58 & Yes & 60 & $\begin{array}{l}\text { Amantadine; } \\
\text { Ropinirole }\end{array}$ \\
\hline JC_0960 & 69 & $\mathrm{~F}$ & 16 & 68 & No & -- & Amantadine \\
\hline
\end{tabular}

Table 1: PD Demographics *Age at date of imaging; \#Unified Parkinson's disease Rating Scale (UPDRS) motor examination score; ** Official age of PD diagnosis unknown recorded first visit to Froedtert \& the Medical College of Wisconsin; $\S=$ Glaucoma Suspect; $\dagger=$ Received Deep Brain Stimulation $\ddagger=$ Likely PD complicated with dementia; ND = No Data).

we continued to investigate other methods to use the retina as a biomarker for PD investigations. The axial length corrected ETDRS regions of $\mathrm{HC}$ subjects and PD patients are shown in Figure 2. Using the ETDRS regions, we investigated the correlation of all measurements for all eyes included in this study, shown in Supplementary Table 1. Due to the high correlation among all measurements, no regions were further collapsed into a single case. We then incorporated logistic regression models using the forward selection method, AIC, and C-statistic criteria for modeling of PD. First, a model containing the 9 measurements in Supplementary Table 1 were generated, and only the superior outer ETDRS region remained in the model as a predictor of PD. Next, the effects of foveal metrics (depth, diameter, and slope) were modeled, and none were significant predictors of PD. Lastly, all
9 measures including foveal metrics were considered for model entry, and again the only significant predictor of $\mathrm{PD}$ was the superior outer ETDRS region measurement with the C-statistic at 0.662 . The crossvalidated C-statistic did not change, and after rounding was also 0.662 .

Due to previous studies showing that females have thinner retinas, sex was added as a predictor to this model [35]. Supplementary Table 2 shows the single predictors of each effect. Following sex the center 1 $\mathrm{mm}$ and temporal outer ETDRS regions, were significant incorporation into this model, this revealed that sex, along with the center and temporal outer regions were significant in predicting $\mathrm{PD}$ (ROC curve shown in Figure 3), with the C-statistic at 0.800 . Two-way interactions between sex, temporal outer, and the center $1 \mathrm{~mm}$ were investigated, but none remained significant. Therefore, when scaled axial length 


\begin{tabular}{|c|c|c|c|}
\hline Foveal Metric & HC subjects & PD patients & $\mathrm{p}$-value \\
\hline Depth - OD (mm) & $0.1078 \pm 0.024$ & $0.1083 \pm 0.021$ & 0.9208 \\
\hline Depth - OS (mm) & $0.1087 \pm 0.026$ & $0.1079 \pm 0.020$ & 0.8968 \\
\hline Diameter - OD (mm) & $1.817 \pm 0.215$ & $1.849 \pm 0.211$ & 0.5150 \\
\hline Diameter - OS (mm) & $1.845 \pm 0.206$ & $1.835 \pm 0.187$ & 0.8321 \\
\hline Slope - OD (deg) & $11.90 \pm 2.79$ & $11.67 \pm 2.48$ & 0.7138 \\
\hline Slope - OS (deg) & $11.86 \pm 3.04$ & $11.70 \pm 2.04$ & 0.8055 \\
\hline Volume - OD $\left(\mathrm{mm}^{3}\right)$ & $0.0748 \pm 0.027$ & $0.0766 \pm 0.026$ & 0.7697 \\
\hline Volume - OS $\left(\mathrm{mm}^{3}\right)$ & $0.0781 \pm 0.027$ & $0.0752 \pm 0.025$ & 0.6673 \\
\hline
\end{tabular}

Table 2: Foveal metrics *Values are reported as mean $\pm 1 S D$. Measurements were compared using a two-tailed t-test with 71 degrees of freedom for the right eye, and 60 degrees of freedom for the left eye).

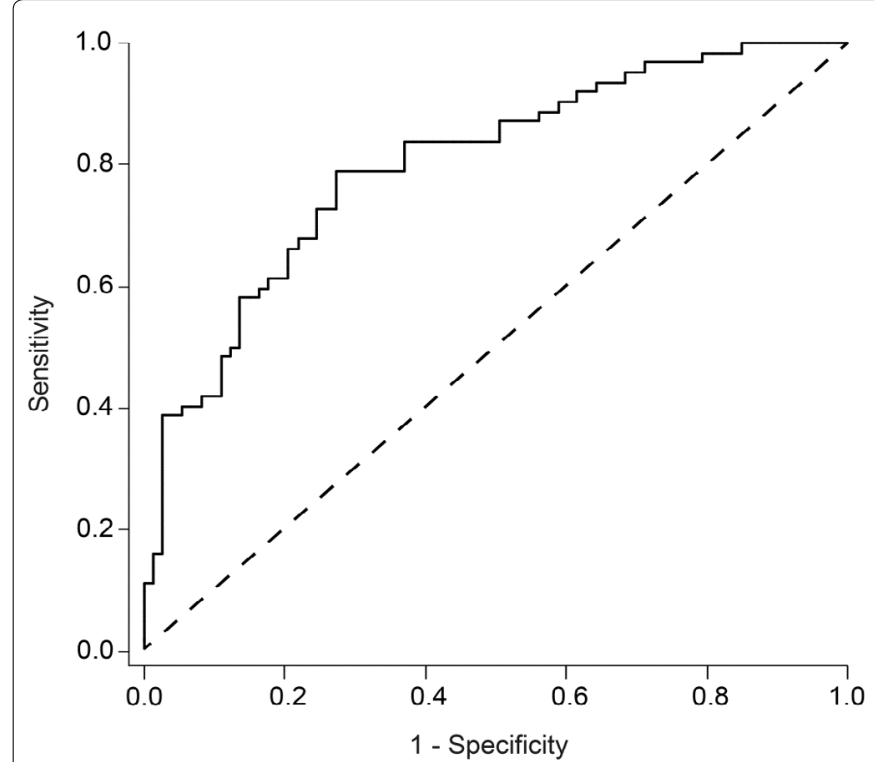

Figure 3: Receiver operating characteristic (ROC) curve using logistic regression models to predict $\mathrm{PD}$. This model incorporates sex, temporal outer, and the center $1 \mathrm{~mm}$ ETDRS region to predict PD. The cross-validated C-statistic is 0.799 (see methods), with a $95 \%$ confidence interval of 0.7928 to 0.8046 . We additionally calculated the odds ratio estimates for these three effects. Sex, temporal outer, and the center $1 \mathrm{~mm}$ ETDRS region had point estimates (and 95\% Wald confidence limits) of 0.094 (0.036 and 0.248$), 0.948$ (0.907 and 0.990$)$, and 0.963 (0.937 and 0.990$)$, respectively. All p-values were less than 0.05 for these effects.

measurements for temporal outer and center ETDRS regions are used, along with a sex correction, the predictive properties are substantially better as compared to the superior outer alone (C-statistic is 0.800 vs. $0.662)$.

\section{Discussion}

In this work, we assessed interocular symmetry, foveal pit morphology, and axial length corrected ETRDS thickness maps in a model to help predict PD using foveal morphology. Our findings add to the growing literature on the topic of utilizing the retina as a non-invasive biomarker to study PD. While there have been reports of interocular asymmetry in foveal thickness in PD [12,20], we did not observe any asymmetry in our PD patients. Furthermore, while foveal morphology has been suggested to be altered in PD [12, 14], we also found no difference in foveal morphology in our PD cohort. These inconsistencies could be due to differences in measurement technique and indicate that a standardized approach would be beneficial in future work. This is particularly important for measurements of the foveal pit, for which there are numerous approaches in the literature [12,35-36,3943].

If the retina is to be used as a biomarker for PD, a model needs to be established to provide the highest possible sensitivity and specificity to ensure reliability in a clinical setting. While the dopaminergic cells in the retina and the relationship to PD need to be further explored, the accessibility of the retina and relative ease of OCT scanning offers a great opportunity for possible early detection of this neurologic condition. In developing an ideal model for predicting PD, axial-length scaling and sex should be incorporated into this model. Scaling for axial-length would provide greater stringency to make sure the retinal measurements are as accurate as possible before providing a prediction of PD. This could significantly reduce the number of false positives or negatives for prospective PD patients with longer or shorter eyes. In addition, factoring for sex into the model provides further accuracy of the results. Our cross-validated statistics revealed that incorporating sex into our model changed the accuracy of PD prediction from 0.662 to 0.800 while also altering which specific ETDRS regions which were significant predictors of PD (superior outer to center $1 \mathrm{~mm}$ and temporal outer). Larger and longitudinal studies need to be performed to accurately determine if the center $1 \mathrm{~mm}$ and temporal outer region are predictors based on this representative population, or if these specific regions could be unique to predicting PD.

Our study had a number of limitations. First, we utilized a relatively small group of subjects. In addition, our cohort of PD patients did not express any visual symptoms that may be described in PD, and they were at varied stages of PD diagnosis. Perhaps in a more severely affected group of patients we may observe some of the retinal changes reported by other groups $[15,18]$. Also, while our subjects were agematched, we did not have sex-matched controls, with most of the HC subjects being women. However, this latter point is unlikely to have affected the main conclusion as sex differences were incorporated into our predictive model.

\section{Conclusion}

Our study demonstrates the need for additional analyses to be performed regarding retinal structure in $\mathrm{PD}$ using quantitative OCT analysis. We believe that the discrepancy between previously published data is due in part to the use of incorrectly scaled OCT data, and propose that OCT devices enable either an export of raw thickness data for offline manipulation or an onboard correction of individual differences in ocular biometry. In addition, uniformity in measurement technique is critical for data sharing and easier comparison of results across studies. Discrepancies and challenges aside, the role of the retina as a biomarker in PD remains an exciting space for continued research. 
Citation: Young JB, Godara P, Williams V, Summerfelt P, Connor TB, et al. (2019) Assessing Retinal Structure in Patients with Parkinson's Disease. J Neurol Neurophysiol 10: 485. doi:10.4172/2155-9562.1000485

\section{Acknowledgements}

The authors would like to acknowledge Erin Curran, Mara Goldberg, and Melissa Wilk, PhD for technical assistance and discussion, along with Noelle Flink and Jeffrey Young, MD, for patient recruitment.

\section{Disclosure of Funding}

Research in this publication was supported in part by the Gene \& Ruth Posner Foundation; Vitreo Retinal Surgery Research Foundation; Unrestricted Departmental Grant from Research to Prevent Blindness. Additional support was provided in part by the National Eye Institute of the National Institutes of Health under award P30EY001931. Its contents are solely the responsibility of the authors and do not necessarily represent the official views of the $\mathrm{NIH}$. This publication was conducted in part in a facility constructed with support from the Research Facilities Improvement Program Grant Number C06RR061511 from the National Center for Research Resources, National Institutes of Health.

\section{References}

1. Parkinson J (2002) An essay on the shaking palsy. J Neuropsychiatry Clin Neurosci 14: 223-236.

2. Nussbaum RL, Ellis CE (2003) Alzheimer's disease and Parkinson's disease. $N$ Engl J Med 348:1356-1364

3. Kowal SL, Dall TM, Chakrabarti R, Storm MV, Jain MV (2013) The current and projected economic burden of Parkinson's disease in the United States. Mov Disord 28: 311-318.

4. Biousse V, Skibell BC, Watts RL, Loupe DN, Drews-Botsch C, et al. (2004) Ophthalmologic features of Parkinson's disease. Neurology 62: 177-180.

5. Archibald NK, Clarke MP, Mosimann UP, Burn DJ (2009) The retina in Parkinson's disease. Brain 132: 1128-1145.

6. Djamgoz MB, Hankins MW, Hirano J, Archer SN (1997) Neurobiology of retinal dopamine in relation to degenerative states of the tissue. Vision Res 37: 35093529.

7. Frederick JM, Rayborn ME, Laties AM, Lam DM, Hollyfield JG (1982) Dopaminergic neurons in the human retina. J Comp Neurol 210: 65-79.

8. Drexler W, Fujimoto JG (2008) State-of-the-art retinal optical coherence tomography. Prog Retin Eye Res 27: 45-88.

9. Tanna H, Dubis AM, Ayub N, Tait DM, Rha J (2010) Retinal imaging using commercial broadband optical coherence tomography. $\mathrm{Br} \mathrm{J}$ Ophthalmol 94 372-376.

10. Aaker GD, Myung JS, Ehrlich JR, Mohammed M, Henchcliffe C, et al. (2010) Detection of retinal changes in Parkinson's disease with spectral-domain optical coherence tomography. Clin Ophthalmol 4: 1427-1432.

11. Albrecht P, Muller AK, Sudmeyer M, Ferrea S, Ringelstein M (2012) Optical coherence tomography in Parkinsonian syndromes. PLoS One 7: e34891.

12. Spund BY, Liu DT, Selesnick I, Glazman S (2013) Remodeling of the fovea in Parkinson disease. J Neural Transm 120: 745-753.

13. Hajee ME, March WF, Lazzaro DR, Shrier EMW (2009) Inner retinal layer thinning in Parkinson disease. Arch Ophthalmol 127: 737-741.

14. Ding Y, Spund B, Glazman S, Shrier EM, Miri S (2014) Application of an OCT data-based mathematical model of the foveal pit in Parkinson disease. J Neural Transm 121: 1367-1376.

15. Garcia-Martin E, Larrosa JM, Polo V, Satue M, Marques ML, et al. (2014) Distribution of retinal layer atrophy in patients with Parkinson disease and association with disease severity and duration. Am J Ophthalmol 157: 470-478.

16. Garcia-Martin E, Satue M, Fuertes I, Otin S, Alarcia R, et al. (2012) Ability and reproducibility of fourier-domain optical coherence tomography to detect retinal nerve fiber layer atrophy in Parkinson's disease. Ophthalmology 119: 2161-2167.

17. Satue M, Garcia-Martin E, Fuertes I, Otin S, Alarcia, et al. (2013) Use of Fourierdomain OCT to detect retinal nerve fiber layer degeneration in Parkinson's disease patients. Eye (Lond) 27: 507-514.

18. Satue M, Seral M, Otin S, Alarcia R, Herrero R, et al. (2014) Retinal thinning and correlation with functional disability in patients with Parkinson's disease. $\mathrm{Br}$ J Ophthalmol 98: 350-355.

19. Roth NM, Saidha S, Zimmermann H, Brandt AU, Isensee J, et al. (2014) Photoreceptor layer thinning in idiopathic Parkinson's disease. Mov Disord 29: 1163-1170.
20. Shrier EM, Adam CR, Spund B, Glazman S, Bodis-Wollner (2012) Interocular asymmetry of foveal thickness in Parkinson disease. J Ophthalmol 84: 57.

21. Lee JY, Kim JM, Ahn J, Kim HJ, Jeon BS, et al. (2014) Retinal nerve fiber layer thickness and visual hallucinations in Parkinson's disease. Mov Disord 29: 61-67.

22. Kirbas S, Turkyilmaz K, Tufekci A, Durmus M (2013) Retinal nerve fiber layer thickness in Parkinson disease. J Neuroophthalmol 33: 62-65.

23. Garcia-Martin E, Satue M, Otin S, Fuertes I, Alarcia R, et al. (2014) Retina measurements for diagnosis of Parkinson disease. Retina 34: 971-980.

24. Kaur MR, Saxena D, Behari SM, Sharma P (2015) Correlation between structura and functional retinal changes in Parkinson disease. J Neuroophthalmol 35 254-258.

25. Jimenez B, Ascaso FJ, Cristobal JA, Lopez del val J (2014) Development of a prediction formula of Parkinson disease severity by optical coherence tomography. Mov Disord 29: 68-74.

26. Sari ES, Koc R, Yazici A, Sahin G, Ermis SS (2015) Ganglion cell-inner plexiform layer thickness in patients with Parkinson disease and association with disease severity and duration. J Neuroophthalmol 35: 117-121.

27. Zivkovic M, Dayanir V, Stamenovic J, Ljubisavljevic S, Prazic A, et al. (2017) Retinal ganglion cell/inner plexiform layer thickness in patients with Parkinson's disease. Folia Neuropathol 55: 168-173.

28. Satue M, Rodrigo MJ, Obis J, Vilades E, Gracia H, et al. (2017) Evaluation of progressive visual dysfunction and retinal degeneration in patients with Parkinson's disease. Invest Ophthalmol Vis Sci 58: 1151-1157.

29. Sevim DG, Unlu M, Gultekin MC, Mirza KM (2017) Evaluation of retinal changes in progressive supranuclear palsy and Parkinson disease. J Neuroophthalmo 38: $151-155$

30. Moschos MM, Chatziralli IP (2017) Evaluation of choroidal and retinal thickness changes in Parkinson's disease using spectral domain optical coherence tomography. Semin Ophthalmol 33: 494-497.

31. Odell D, Dubis AM, Lever JF, Stepien KE, Carroll J (2011) Assessing errors inherent in OCT-derived macular thickness maps. J Ophthalmol 69: 25-74.

32. Cole BL, Lian KY, Lakkis C (2006) The new richmond HRR pseudoisochromatic test for colour vision is better than the Ishihara test. Clin Exp Optom 89: 73-80.

33. Neitz M, Neitz J (2001) A new mass screening test for color-vision deficiencies in children. Color Research and Application 26: 239-249.

34. Ferris FL, Davis MD, Clemons TE, Lee LY, Chew EY, et al. (2005) A simplified severity scale for age-related macular degeneration: AREDS Report No. 18. Arch Ophthalmol 123: 1570-1574

35. Wagner-Schuman M, Dubis AM, Nordgren RN, Lei Y, Odell D, et al. (2011) Race and sex-related differences in retinal thickness and foveal pit morphology. Invest Ophthalmol Vis Sci 52: 625-634.

36. Wilk MA, McAllister JT, Cooper RF, Dubis AM, Patitucci TN, et al. (2014) Relationship between foveal cone specialization and pit morphology in albinism. Invest Ophthalmol Vis Sci 55: 4186-4198.

37. Bland JM, Altman DG (1986) Statistical methods for assessing agreement between two methods of clincial measurement. Lancet 1: 307-310.

38. Giavarina D (2015) Understanding Bland Altman analysis. Biochemia Medica 25: 141-151.

39. Tick S, Rossant F, Ghorbel I, Gaudric A, Sahel JA, et al. (2011) Foveal shape and structure in a normal population. Invest Ophthalmol Vis Sci 52: 5105-5110.

40. Dubis AM, McAllister JT, Carroll J (2009) Reconstructing foveal pit morphology from optical coherence tomography imaging. Br J Ophthalmol 93: 1223-1227.

41. Hammer DX, Iftimia NV, Ferguson RD, Bigelow CE, Ustun TE, et al. (2008) Foveal fine structure in retinopathy of prematurity: An adaptive optics fourier domain optical coherence tomography study. Invest Ophthalmol Vis Sci 49 : 2061-2070.

42. Gupta A, Laxmi G, Nittala MG, Raman R (2011) Structural and functional correlates in color vision deficiency. Eye (Lond) 25: 909-917.

43. Thomas MG, Kumar A, Mohammad S, Proudlock FA, Engle EC, et al. (2011) Structural grading of foveal hypoplasia using spectral-domain optical coherence tomography a predictor of visual acuity? Ophthalmology 118: 1653-1660. 